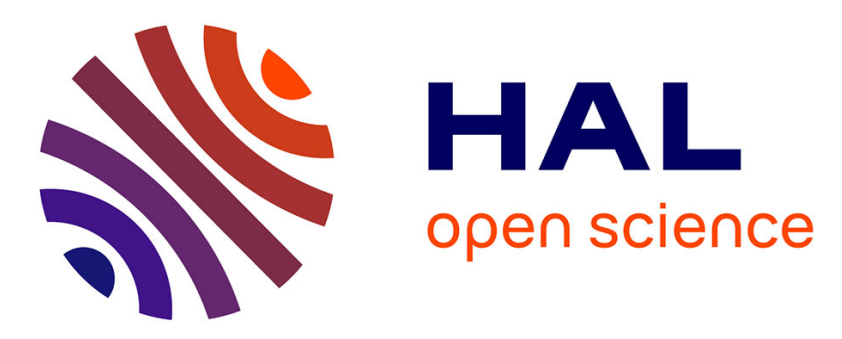

\title{
Interest in intermediate soft-classified maps in land change model validation: suitability versus transition potential
}

\author{
M T Camacho Olmedo, Martin Paegelow, J F Mas
}

\section{- To cite this version:}

M T Camacho Olmedo, Martin Paegelow, J F Mas. Interest in intermediate soft-classified maps in land change model validation: suitability versus transition potential. International Journal of Geographical Information Science, 2013, 27 (12), pp.2343-2361. 10.1080/13658816.2013.831867 . hal-03158891

\author{
HAL Id: hal-03158891 \\ https://hal.science/hal-03158891
}

Submitted on 4 Mar 2021

HAL is a multi-disciplinary open access archive for the deposit and dissemination of scientific research documents, whether they are published or not. The documents may come from teaching and research institutions in France or abroad, or from public or private research centers.
L'archive ouverte pluridisciplinaire $\mathbf{H A L}$, est destinée au dépôt et à la diffusion de documents scientifiques de niveau recherche, publiés ou non, émanant des établissements d'enseignement et de recherche français ou étrangers, des laboratoires publics ou privés. 


\title{
Interest in intermediate soft-classified maps in land change model validation: suitability versus transition potential
}

\author{
M.T. Camacho Olmedo ${ }^{\mathrm{a} *}$, M. Paegelow ${ }^{\mathrm{b}}$ and J.F. Mas \\ ${ }^{a}$ Dpto. Análisis Geográfico Regional y Geografía Física, Universidad de Granada, Granada, Spain; \\ ${ }^{b}$ GEODE UMR 5602 CNRS, Université de Toulouse, Toulouse, France; ${ }^{c}$ Centro de Investigaciones \\ en Geografia Ambiental, Universidad Nacional Autónoma de México (UNAM), Morelia, México
}

(Received 15 June 2012; accepted 28 July 2013)

\begin{abstract}
This study compares two types of intermediate soft-classified maps. The first type uses land use/cover suitability maps based on a multi-criteria evaluation (MCE). The second type focuses on the transition potential between land use/cover categories based on a multi-layer perceptron (MLP). The concepts and methodological approaches are illustrated in a comparable manner using a Corine data set from the Murcia region $\left(2300 \mathrm{~km}^{2}\right.$, Spain) in combination with maps of drivers that were created with two stochastic, discretely operating, commonly used tools (MCE in CA_MARKOV and MLP in Land Change Modeler). The importance of the different approaches and techniques for the obtained results is illustrated by comparing the specific characteristics of both approaches by validating the suitability versus transition potential maps to each other using a Spearman correlation matrix and, between the Corine maps, using classical ROC (receiver operating characteristic) statistics. Then, we propose a new use of ROC statistics to compare these intermediate soft-classified maps with their respective hard-classified maps of the models for each category. The validation of these results can be beneficial in choosing a suitable model and provide a better understanding of the implications of the different modeling steps and the advantages and limitations of the modeling tools.
\end{abstract}

Keywords: intermediate soft-classified maps; suitability; transition potential; validation; land change model

\section{Introduction}

A large panel of software tools is currently available for land change modeling. In the context of spatiotemporal modeling, a review of the methods and tools used to perform simulations highlights the principal choices that are involved, including how the model is evaluated. Recently, there has been increasing interest in the validation of simulation models that predict changes over time, particularly from an initial time to a later time (Pontius and Petrova 2010), with a focus on land use and cover change (LUCC), i.e., land change (Jansen and Veldkamp 2011).

We can distinguish two types of model outputs that are both predicted at a future time: outputs called hard-classified maps, in which each pixel in a raster map is assigned to a discrete number of classes that are the same at any time step, and outputs called softclassified maps, in which each pixel in a raster map corresponds to probabilities that are

\footnotetext{
*Corresponding author. Email: camacho@ugr.es
} 
predicted for the classes. Both hard and final soft results refer to the validation period, i.e., extrapolation from the later known date to a future date denoted as T, because of the quantity of the changes/demands that are estimated and their allocations.

In this study, we focus on a type of intermediate softened images that can represent the conceptual core of these tools. These images are rank-order indices and do not refer to a concrete future date. Our interest is particularly the difference between two specific results: suitability versus transition potential images.

A suitability image communicates the most appropriate use of a parcel of land as judged by a subjective decision based on knowledge or opinion, that is, it determines to what extent a given piece of land is suitable for a specific use (Steiner et al. 2000). Suitability is not designed necessarily for prediction, since humans frequently use land for purposes that are not suitable and this does not consider past history necessarily. Nevertheless, several land change models are based on suitability maps (Conway and Wellen 2011, Yu et al. 2011) and therefore researches incorporate information from a previous time period, termed the training or calibration period $t_{0}-t_{1}$ or, more frequently, from the last date $t_{1}$ in the intermediate soft maps to improve predictions (Paegelow and Camacho Olmedo 2005; Villa et al. 2007). The inclusion of this information from the calibration period or from the last date produces not a pure suitability map but a suitability map that can pay partial attention to human uses implemented that are not suitable but are common.

A transition potential image communicates a researcher's opinion based on knowledge of the relative likelihood of transition of one parcel relative to another (Eastman et al. 2005, Sangermano et al. 2010, Wang and Mountrakis 2011). The transition potential is considered to communicate the likely future based on an extrapolation from information of LUCC observed during the calibration period $\mathrm{t}_{0}-\mathrm{t}_{1}$.

These maps, which are generally produced through the calibration step, may also be used in forecasting simulations as part of validation techniques, which is one of the keys to land change modeling. Even calibration can often involve validation (Crooks and Heppenstall 2012); therefore, assessment methods are necessary to acquire these types of results. Several studies have focused exclusively on soft simulation results and their validation (Conway and Wellen 2011, Wang and Mountrakis 2011, Pérez-Vega et al. 2012).

With these aims, in this study we use different models, an approach that has been used in relatively few previous studies (Pontius and Malanson 2005, Villa et al. 2006, Paegelow and Camacho 2008, Pontius et al. 2008, Mas et al. 2011, Wang and Mountrakis 2011). We compare suitability and transition potential images, modeling the land use and cover (LUC) state and the transitions, respectively, which are produced by multi-criteria evaluation (MCE) in CA_MARKOV and multi-layer perceptron (MLP) in Land Change Modeler (LCM), respectively. Both are available in the IDRISI GIS system. CA_MARKOV produces only suitability images as softened results. LCM produces two types of soft results: a transition potential as intermediate soft images for each modeled transition and an overall change potential image that takes into account all of the transitions. This overall change potential image is formed at the same time as hard predictions in the change allocation step.

Additionally, we validate the results by applying several assessment methods to different objects, including real-world and hard-classified maps and the two softened map results. Our goal is to compare the suitability and transition potential map validity in terms of a change potential evaluation and an initial approximation of their relationship with the change allocation results, that is, hard classification with respect to the simulation step.

In Section 2, we describe the models and the study area. Then, the practical application to our data set is explained, including the methods used to calculate suitability and 
potential for transition maps, and we briefly describe the hard-classified output. The validation methods used in this study are also presented in this section. Results and validation are presented in Section 3. Sections 4 and 5 are focused on a discussion of the principal results and conclusions, respectively.

\section{Methods}

\subsection{The models: MCE in CA_MARKOV and MLP in LCM}

To address the research question, the framework of this work is a comparison of two modeling approaches with discrete time and stochastic methods to predict the future LUC area. These methods are widely available as two IDRISI modules (Eastman 2009) and are among the most commonly used modeling tools: CA_MARKOV and LCM. To allocate the changes in space, the first approach uses suitability maps for each LUC category based on a supervised MCE. The second approach generates the transition potential from one land use category to another using MLP.

Both approaches require an analysis of the explanatory variables that can possibly account for the occurrence of LUC or LUC changes. Nevertheless, these methods are substantially different. CA_MARKOV requires a series of suitability images for each LUC category. This information can be produced in different ways, including manually created maps, the results of statistical methods and, more generally, maps that are derived from an MCE. An MCE splits explanatory variables into constraints, which are binary maps that act as masks, and factors expressing the variable suitability over space. For further information about MCE, see Eastman et al. (1995), Eastman (1996), Gómez and Barredo (2005) and Paegelow and Camacho (2005). CA_MARKOV is considered to be a more supervised tool ${ }^{1}$ than LCM.

LCM offers the possibility of integrating various transitions involving the same explanatory variables into one sub-model. Then, the model computes the transitional, sub-model-specific measures of the driver impact using various methods, e.g., natural logarithmic and evidence likelihood. Additionally, LCM offers the possibility of training the model using logistic regression, SimWeight, which is a machine learning procedure, and an MLP. LCM is considered to be a more automated tool ${ }^{2}$ than CA_MARKOV.

For hard-classified map results, both approaches can use the same Markov chain matrices for quantity of change estimations. Next, the same multi-objective land allocation mechanism is applied to allocate these changes based on the choice of the most suitable pixels, i.e., those pixels with the greatest potential for the occurrence of LUC or LUC changes, and to solve the incompatibilities between the different uses or transitions. ${ }^{3}$

\subsection{Study area, model of land use and data}

The two modeling approaches and their calibrations are based on LUC knowledge of the different time steps and the related explanatory variables. We use two LUC maps from time $t_{0}$ for 1990 and time $t_{1}$ for 2000 to simulate the LUC during 2000-2006 (2006 denoted as T) for a $2300-\mathrm{km}^{2}$ area in the Spanish autonomous community of Murcia (Figure 1). The LUC maps include seven categories that were used in the Corine Land Cover data set: (1) Urban, industrial and transport uses; (2) Wooded land; (3) Grassland and Scrub; (4) Unproductive; (5) Irrigated crops; (6) Rain-fed crops; and (7) Surface water and wetlands. A Corine LUC map from 2006 was used to validate the resulting simulations. The surface per category for the three dates is shown in Figure 2, and larger transitions between 1990-2000 and 2000-2006 are shown in Figure 3. 

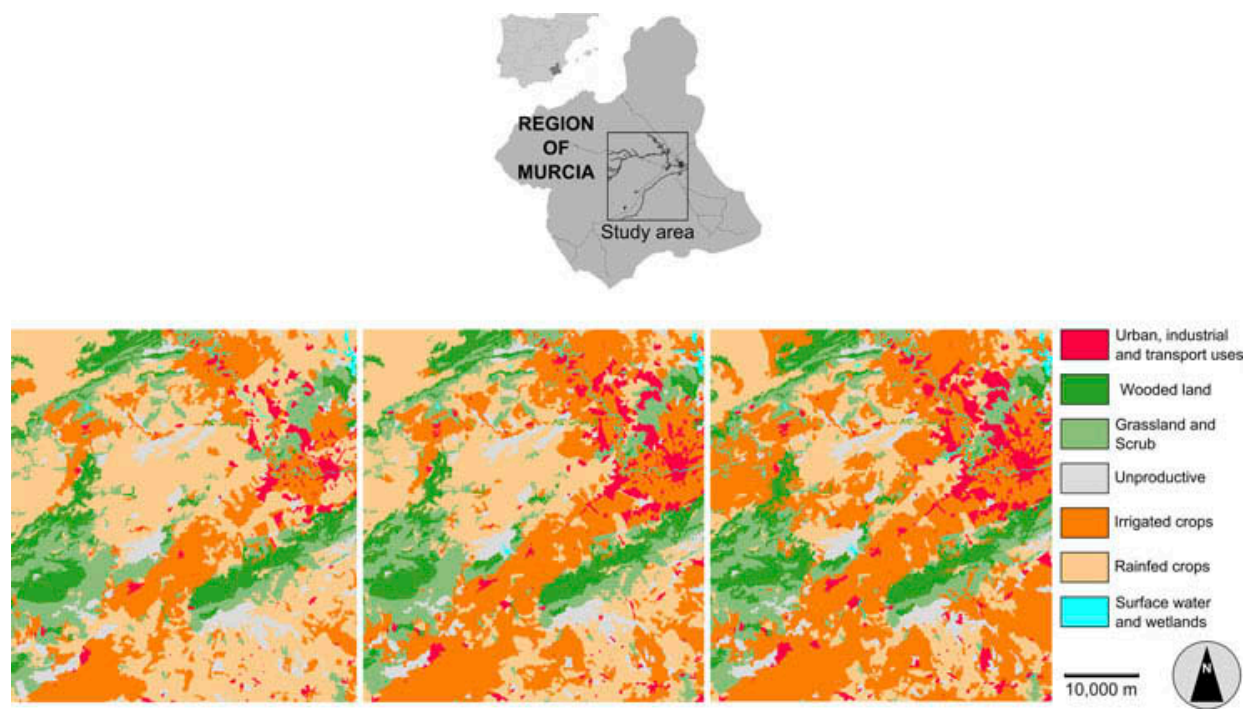

Figure 1. Location of the study area (Spain). LUC in 1990 (left), 2000 (middle), and 2006 (right). (1) Urban, industrial and transport uses; (2) Wooded land; (3) Grassland and Scrub; (4) Unproductive; (5) Irrigated crops; (6) Rain-fed crops; (7) Surface water and wetlands.

Source: Corine Land Cover.

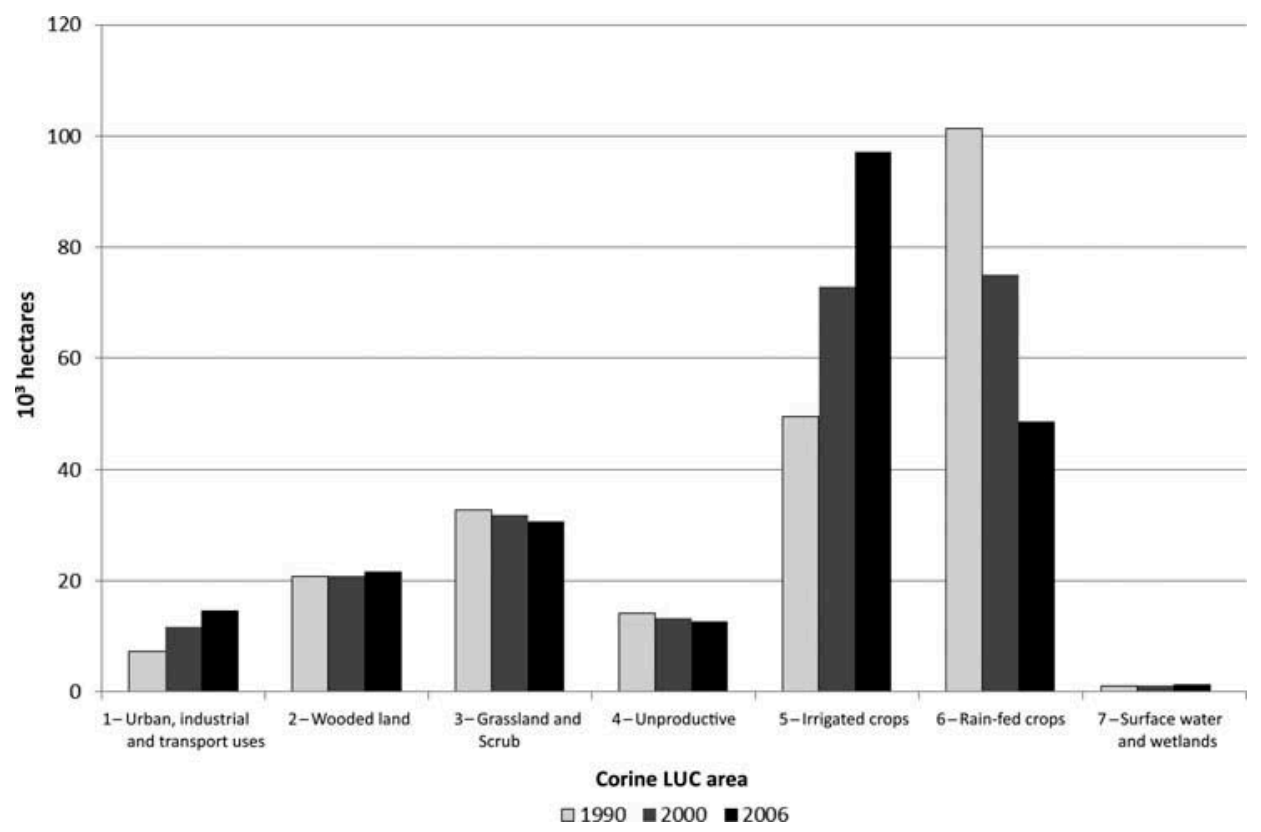

Figure 2. Corine LUC area (10 ${ }^{3}$ hectares $)$ in 1990, 2000, and 2006.

The choice of explanatory variables is based on the methodological orientation (Pontius et al. 2008), availability of geo-referenced data (Gómez and Grindlay 2008) and previous work from the given workspace. ${ }^{4}$ Variables are topographic variables, protected area maps, accessibility and road distance maps and hydrological distance maps. 


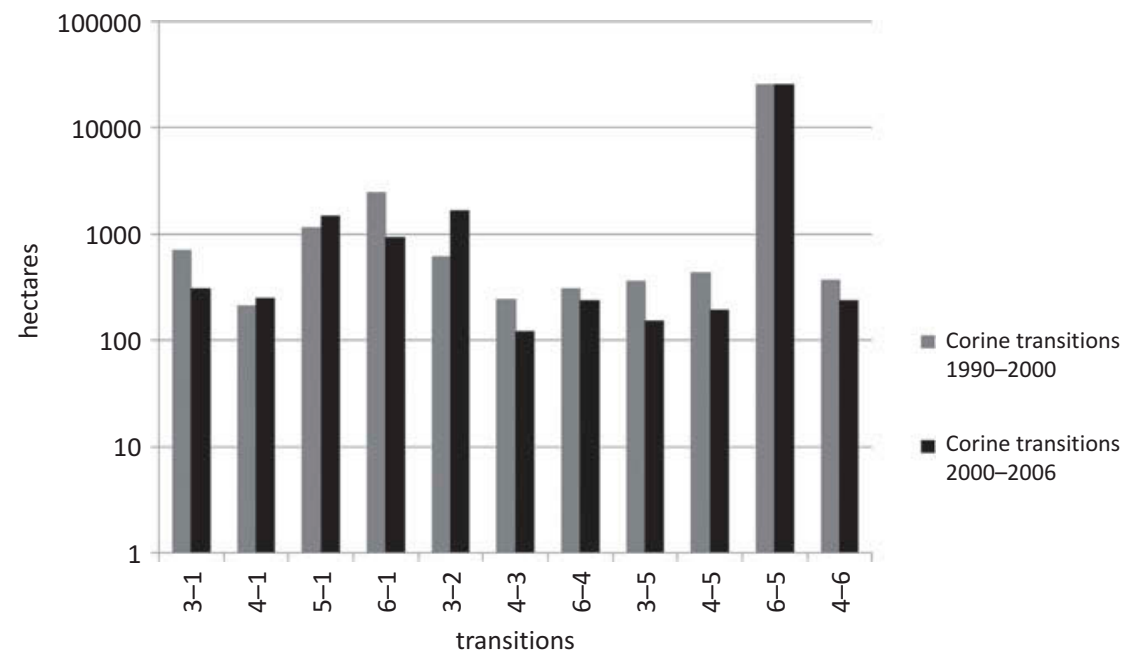

Figure 3. Corine area (hectares) of larger transitions between 1990-2000 and 2000-2006.

\subsection{Managing variables to obtain suitability and transition potential maps}

Despite their fundamental methodological differences, we employed the MCE and MLP models in manners as similar as possible to each other and avoided addressing their specific characteristics. Thus, neither model was used to its fullest potential. However, this approach has the advantage of reducing the differences among the majority of stages, which allows the identification of model specificities in the soft results, suitability in MCE and transition potential in MLP, and their corresponding processes: an MCE versus an MLP.

We used the following procedure to obtain suitability and transition potential maps. First, the degree of equivalence is established between the suitability for a specific use and the general dynamics to which the transitions refer. MCE is applied to obtain seven suitability maps, one per LUC category. In the practical application of MLP, six sub-models are applied, one per dynamic, whereas 11 transition potential maps, one per transition, are returned. These transitions were chosen among the total transitions based on their large surfaces and suitable processes of change (Table 1).

Second, we used evidence likelihood to transform the explanatory variables into factors. This procedure analyzes the relative frequency of pixels that belong to the different categories of that variable within the areas of LUC change or LUC occurrence. It is an efficient method to incorporate categorical variables into the analysis, and it accepts continuous variables that have been binned into categories. We also use evidence likelihood to obtain degrees of restriction, as used in a fuzzy analysis. Despite this common choice of evidence likelihood transformation, the reference maps, that are binary maps, are different for MCE and MLP. For MCE, the reference map is the most recent land use category, LUC at $t_{1}$. For MLP, the chosen reference map is a map of transitions that are considered in a sub-model during the calibration period $t_{0}-t_{1}$. This option aims to preserve the nature of state of the categories in suitability and the changing categories in transition potential.

The Pearson correlation is calculated between all pairs of factors per suitability map and sub-model (Table 2), with the exception of suitability map 7 because of the absence of an equivalent transition. These values indicate that the choice of cited reference maps can affect the similarity or dissimilarity of these factors. Figure 4 shows an example of two 
Table 1. Equivalence between the LUC suitability maps (columns) and transitions from 1990-2000 (rows). The general dynamics (in boxes) are the sub-models in LCM: the legend ranges from 1 (urban growth) to 6 (new rain-fed crops). The LUC suitability 7 does not have equivalence with any transition.

\begin{tabular}{|c|c|c|c|c|c|c|}
\hline $\begin{array}{l}\text { Suitability } \\
\text { (col) }\end{array}$ & & & & & & \\
\hline $\begin{array}{l}\text { Transitions } \\
(90-00) \\
\text { (rows) }\end{array}$ & $\begin{array}{l}1 \text { Urban, } \\
\text { industrial and } \\
\text { transport uses }\end{array}$ & $\begin{array}{l}2 \text { Wooded } \\
\text { land }\end{array}$ & $\begin{array}{l}3 \text { Grassland } \\
\text { and Scrub }\end{array}$ & 4 Unproductive & $\begin{array}{l}5 \text { Irrigated } \\
\text { crops }\end{array}$ & $\begin{array}{l}6 \text { Rain-fed } \\
\text { crops }\end{array}$ \\
\hline $\begin{array}{l}3 \text { to } 1 \\
4 \text { to } 1 \\
5 \text { to } 1 \\
6 \text { to } 1\end{array}$ & $\begin{array}{l}1 \text { Urban } \\
\text { growth }\end{array}$ & & & & & \\
\hline 3 to 2 & & $\begin{array}{l}2 \text { Forest } \\
\text { regeneration }\end{array}$ & & & & \\
\hline 4 to 3 & & & $\begin{array}{l}3 \text { Grassland } \\
\text { and } \\
\text { scrub } \\
\text { regeneration }\end{array}$ & & & \\
\hline 6 to 4 & & & & $\begin{array}{l}4 \text { Human } \\
\text { intervention }\end{array}$ & & \\
\hline $\begin{array}{l}3 \text { to } 5 \\
4 \text { to } 5 \\
6 \text { to } 5\end{array}$ & & & & & $\begin{array}{l}5 \mathrm{New} \\
\text { irrigation } \\
\text { and rain-fed } \\
\text { irrigation } \\
\text { change }\end{array}$ & \\
\hline 4 to 6 & & & & & & $\begin{array}{l}6 \mathrm{New} \\
\text { rain-fed } \\
\text { crops }\end{array}$ \\
\hline
\end{tabular}

factors that are extracted from the digital elevation model (DEM) for MCE and for MLP in suitability and sub-model map 4, respectively, that show that no linear relationship exists between them (Pearson value of 0.0324). The reference maps, real LUC 4 in 2000 (left) and real transition of 1990-2000 from 6 to 4 (right), are superimposed in red.

Another difference between MCE and MLP is that MLP assigns a value of 0 to not candidates for the land transition. To mitigate this difference, we introduce a constraint in MCE corresponding to these not candidates for the land transition. It should be noted that this difference mainly affects the target category, which is given a value of 0 in MLP because this category has a null transition potential, whereas it is given a value of up to 1 in MCE.

Finally, in MCE, the user can input factor weighting. By contrast, MLP automatically evaluates and weights each factor and implicitly takes into account the correlations between the explanatory maps. Previously, MLP has offered Cramer's V between the factors and the later LUC map, LUC at $t_{1}$, i.e., a quantitative measure that indicates how much the first ones are relevant to the second one. This feature is one of the main differences between both modules. To mitigate this difference, we use Cramer's V of the collection of factors 
Table 2. Explanatory variables for each suitability map (MCE) and sub-model (MLP). Pearson correlation values of every pair of factors obtained by evidence likelihood are included in boxes. For the MCE factors, the reference map chosen is LUC at $2000\left(t_{1}\right)$. For the MLP factors, the reference map chosen is the transition during $1990-2000\left(\mathrm{t}_{0}-\mathrm{t}_{1}\right)$.

\begin{tabular}{|c|c|c|c|c|c|c|}
\hline \multirow[b]{2}{*}{ Explanatory variables } & \multicolumn{6}{|c|}{$\begin{array}{l}\text { Pearson correlation values of every pair of factors } \\
\text { between suitability (MCE) and sub-model (MLP) }\end{array}$} \\
\hline & 1 & 2 & 3 & 4 & 5 & 6 \\
\hline Elevation & 0.9047 & 0.7995 & 0.4127 & 0.0324 & 0.9263 & 0.1596 \\
\hline Slope & 0.9988 & 0.9575 & 0.9746 & 0.8450 & 0.9959 & 0.8637 \\
\hline Aspect & 0.9131 & 0.9119 & 0.8028 & 0.3313 & 0.9235 & 0.7378 \\
\hline Protected areas & 1.0000 & 1.0000 & 1.0000 & 1.0000 & 1.0000 & 1.0000 \\
\hline Accessibility to principal dirt & 0.9620 & & & & & \\
\hline Accessibility to human settlements & 0.9703 & & & & & \\
\hline Distance to secondary dirt road & 0.9851 & & & & 0.9992 & 0.4663 \\
\hline Distance to Taibilla Channel & 0.9830 & & & & 0.9562 & 0.2149 \\
\hline Distance to irrigation channels & & & & & 0.8174 & \\
\hline Distance to network of rivers and streams & & & & & 0.9850 & \\
\hline Distance to network of ditches & & & & & 0.9821 & \\
\hline Distance to catchments & & & & & 0.9966 & \\
\hline Irrigation community map & & & & & 1.0000 & \\
\hline Aquifers map & & & & & 1.0000 & \\
\hline
\end{tabular}
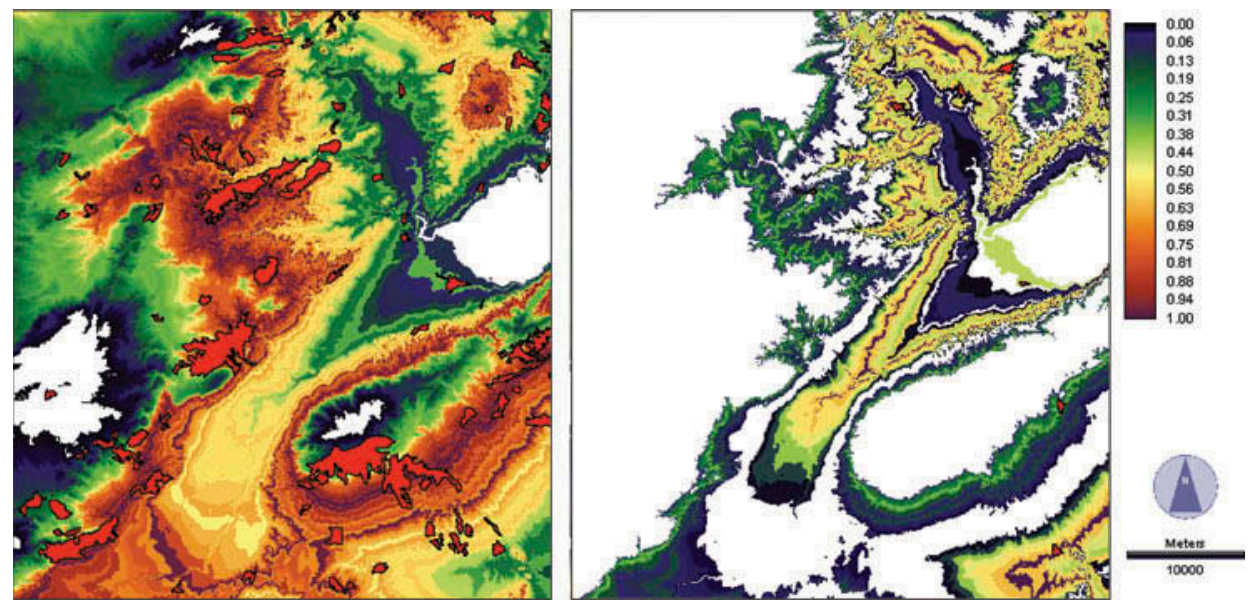

Figure 4. Empirical likelihood of the real LUC 4 in 2000 derived from DEM (left); and of the real transition of 1990-2000 from 6 to 4 derived from DEM (right). The reference maps, real LUC 4 in 2000 (left) and real transition of 1990-2000 from 6 to 4 (right), are superimposed in red.

for each LUC to obtain the weights using the Saaty method under the analytical hierarchy process (AHP) and we introduce them into the weighted linear combination (WLC) of MCE.

\subsection{Obtaining hard-classified maps}

For the hard-classified maps, the same Markovian matrix (Table 3) is used in CA_MARKOV and LCM to compute the transition probabilities and transition cell 


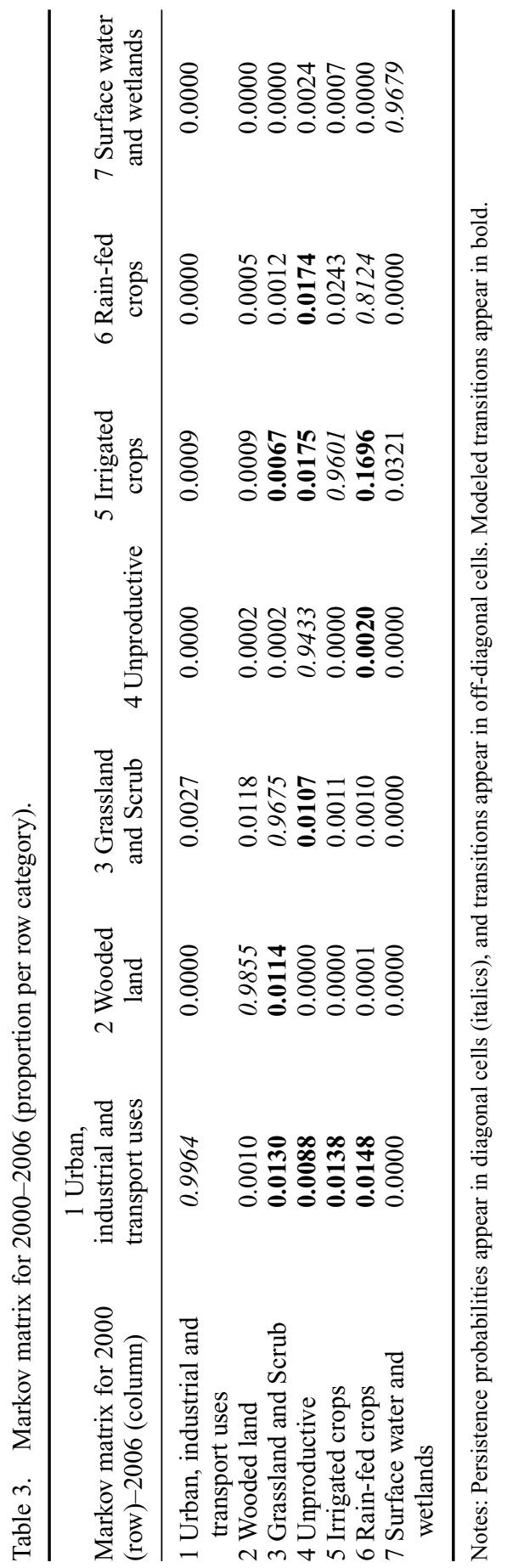


numbers between the LUC categories. Additionally, both models resolve incompatibilities between different uses or transitions using the same multi-objective evaluation algorithm. The difference concerns the cellular automaton (CA) that is included in CA_MARKOV. The default $5 \times 5$ filter is applied for the hard-classified CA_MARKOV simulation. The filter is applied for each binary LUC map that is temporally extracted from the simulated LUC map. Applying this contiguous filter, the considered LUC category loses and gains pixels depending on the filter design and suitability maps that are used to conform the resulting map to the Markov chain-predicted LUC areas.

\subsection{Validation methods}

Two types of areas will be validated. The first type constitutes the candidate for change areas, which are the common points for comparing both types of results, and which correspond to Corine LUC at $t_{1}$ pixel candidates for modeled transitions. The second type constitutes the total areas, candidate for change areas and candidate for persistence areas, the last one corresponding to Corine LUC at $t_{1}$ target use. Only suitability maps include the total area that will be used for a better understanding of this result comparing it to the MCE results for the candidate for change areas only.

Masking with not candidate LUC or not candidate land change is used for all of the assessment methods.

\subsubsection{Assessment of the congruence of different model outputs}

Taking into account that the two intermediate soft images are rank-order indices, we use an assessment method that focuses on the similarity or correspondence between them, calculating the Spearman rank correlation coefficient, a nonparametric measure that assesses how well the relationship between both images can be described by a monotonic, not necessarily linear, function. A Spearman correlation of zero indicates that there is no monotone function between both images. The Spearman correlation increases in magnitude when values of both images become closer to being perfect monotone functions of each other, i.e., a correlation of +1 or -1 . This ordinal correlation analysis can be an initial approach to evaluate the degree of similarity between the two maps, and this type of analysis might be an adequate assessment method in the context of model land change (Conway and Wellen 2011).

In this work, we obtain Spearman correlation values between the LUC suitability and modeled transition potential for candidate for change areas only and graph their relationships through scattergrams.

\subsubsection{Assessment by real data}

For these intermediate softened maps, a full validation assumes two unique characteristics: (1) these maps do not refer to a future concrete date but will be validated with future concrete maps, and (2) these maps are rank-order indices, but real land use typically includes a categorical legend. We expect that each category or real transition will be allocated where the values are highest in soft-classified maps; by contrast, other categories or transitions will be allocated where the values are lower. Validation methods must then compare a rank image with a Boolean image where that category or real transition is located.

In this study, we apply a tested and robust index that is the main appropriate technique to compare rank-order variables: ROC (receiver operating characteristic) and, specifically, 
the area under the ROC curve (AUC), that is a summary metric (Pontius and Parmentier in press). An AUC value of 0.5 indicates complete randomness between two maps, whereas a value of 1 indicates perfect spatial agreement (Swets 1988, Pontius and Schneider 2001, Jansen and Veldkamp 2011). Values lower than 0.5 indicate a systematically incorrect model (Eastman et al. 2005). ROC is a powerful calibration tool because it allows the measurement of how well a suitability map that expresses the training knowledge agrees with the initial model's known conditions (Pontius and Schneider 2001).

ROC is applied to compare intermediate soft-classified maps to Corine data in a classical manner. Focusing on candidate for change areas, the AUC values were computed for Corine binary transition maps from time $t_{1} 2000$ to time T 2006 and sub-models obtained using MLP and MCE suitability maps. The AUC values were also calculated based on a category-by-category comparison of Corine binary LUC maps from 2006 with MCE suitability maps. In this case, we validated the LUC state, including the candidate for change and persistence areas.

A mask for background pixels or for pixels which are not candidates in the softclassified map has been used. A threshold of 10 is selected for all treatments, that is, each bin contains $10 \%$ of the candidate region. This is an equal threshold width option that means that the percentage of highest pixels in the soft images to be compared with the reference image will be $10 \%$ in the first threshold, and this width will be added on to each subsequent threshold until $100 \%$.

\subsubsection{Assessment of the different outputs from the same model}

In the present study, we propose a new use of the ROC index in comparing soft-classified maps to hard-classified maps to assess their relationship. It must be borne in mind that the intermediate soft-classified maps do not refer to a future specific date and reference maps for obtaining factors are LUC at $t_{1}$ in suitability maps and the calibration period $t_{0}-t_{1}$ in transition potential maps. The hard-classified maps refer to the validation period $t_{1}-T$, because of the quantity of the changes/demands that are estimated and their allocations. For the candidate for change areas, binary maps are those of the simulated land changes in CA_MARKOV and the simulated land changes in LCM maps, which are compared to the suitability maps and sub-model maps, respectively. For the total areas, candidate for change and persistence areas, the AUC value is obtained by comparing the simulated LUC in 2006 by CA_MARKOV with the suitability maps. A threshold of 10 is also selected for all treatments, that is, each bin contains $10 \%$ of the candidate region.

\section{Results}

\subsection{Suitability versus transition potential maps and hard-classified maps}

The MCE results are suitability maps for seven land uses; however, the suitability map 7, i.e., Surface water and wetlands category, will not be considered for validation because there is no transition potential equivalent. This method was applied to every transition submodel, yielding 11 transition potential maps that reflect the change potential over space and time (Table 1). To compare the results, overall map grouping transitions by general dynamics, i.e., sub-models, are formed by simple union (Figure 5).

CA_MARKOV and LCM hard-classified maps for time T 2006 are also obtained. For detecting error and correct prediction (Pontius et al. 2008), observed persistence and 


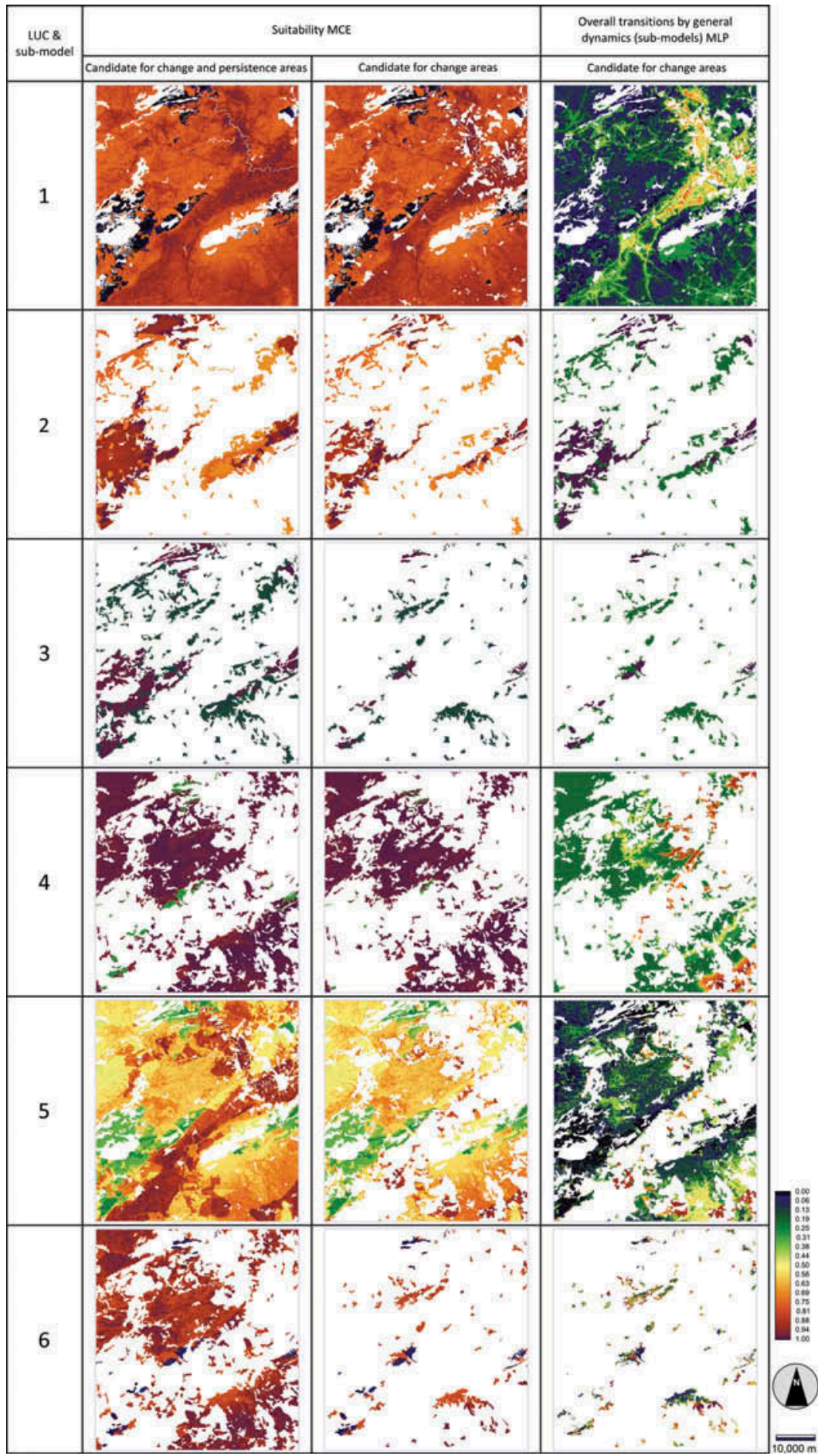

Figure 5. Suitability maps (MCE) (left and center) and sub-model maps (MLP) (right). Candidate for change and candidate for persistence areas (left) correspond to Corine LUC at $t_{1}$ pixel candidates for modeled transitions and to Corine LUC at $t_{1}$ target use, respectively. Candidate for change areas (center and right) correspond to Corine LUC at $t_{1}$ pixel candidates for modeled transitions. White areas correspond to not candidate LUC or not candidate land change. 

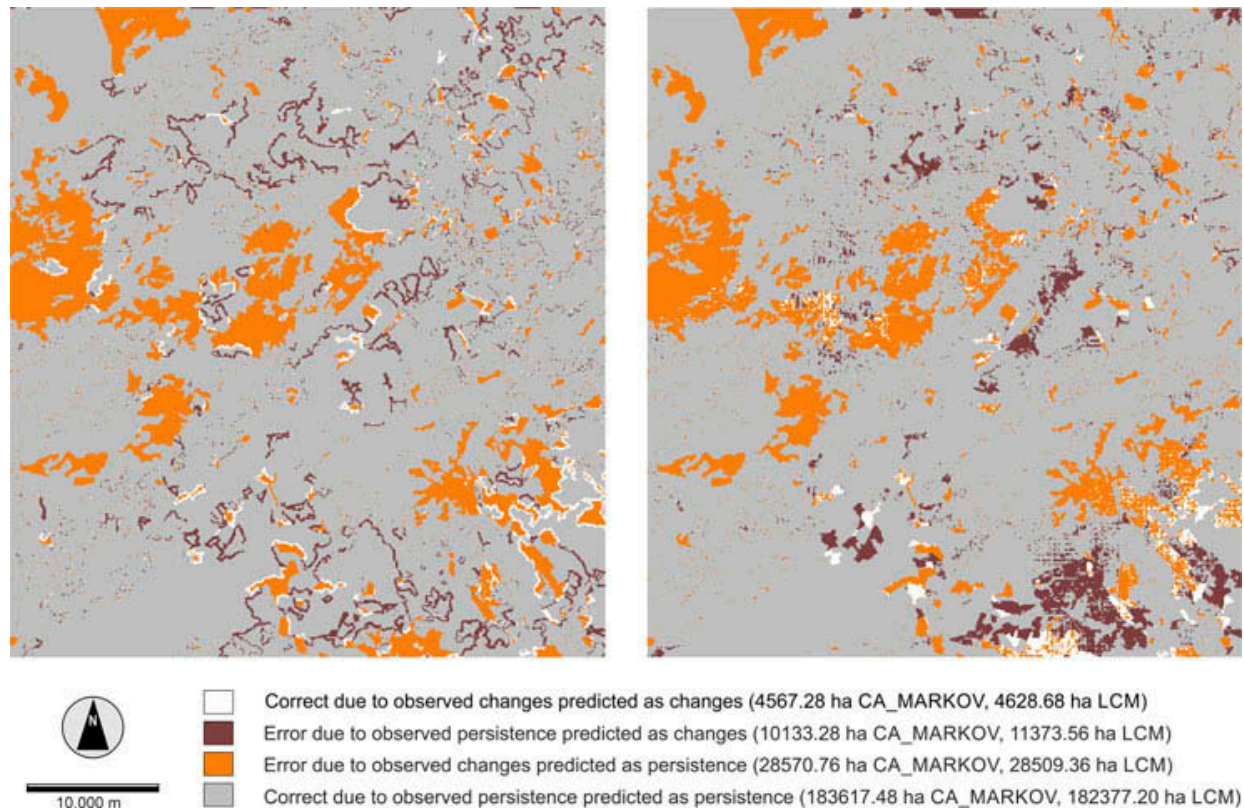

Correct due to observed changes predicted as changes ( 4567.28 ha CA_MARKOV, 4628.68 ha LCM)

Error due to observed persistence predicted as changes (10133.28 ha CA_MARKOV, 11373.56 ha LCM) Error due to observed changes predicted as persistence (28570.76 ha CA_MARKOV, 28509.36 ha LCM)

$10,000 \mathrm{~m}$

Correct due to observed persistence predicted as persistence ( 183617.48 ha CA_MARKOV, 182377.20 ha LCM)

Figure 6. Observed persistence and changes from 2000 to 2006 crossed with predicted persistence and changes from 2000 to 2006 based on CA_MARKOV (left) and LCM (right) (hectares).

changes from 2000 to 2006 are crossed with predicted persistence and changes from 2000 to 2006 based on LCM (left) and CA_MARKOV (right) simulation in Figure 6.

The correct prediction corresponds to observed changes predicted as changes, where LCM is slightly more accurate than CA_MARKOV, and to observed persistence predicted as persistence, where CA_MARKOV is slightly more accurate than LCM. The error prediction corresponds to observed persistence predicted as changes, where LCM shows more errors than CA_MARKOV, and to observed changes predicted as persistence, where CA_MARKOV shows more errors than LCM. The figure of merit (Pontius et al. 2008), which expresses values ranging from 0 (no overlap) to $100 \%$ (perfect overlap) between the observed and predicted change, is $10.5549 \%$ for CA_MARKOV simulation and $10.3988 \%$ for LCM simulation.

The total surface of errors highlights that the Corine quantity of change was much larger than that of the simulated change. A complete hard-classified validation, which is not the scope of the present work, could explain this fact analyzing Markov transitions with respect to Corine transitions for the validation period, particularly if Corine transitions do not show a linear behavior. The accuracy of the estimation of Markov transitions is limited by the fact that the Markov chain does not extrapolate the observed nonlinear transitions.

\subsection{Validation}

3.2.1. Agreement between the LUC suitability and the modeled transition potential for candidate for change areas

The Spearman correlation values and scattergrams (Figure 7) indicate that for sub-models and suitability maps 2,5 , and 6 , the same areas exhibit a low or high susceptibility to 
1. Urban growth

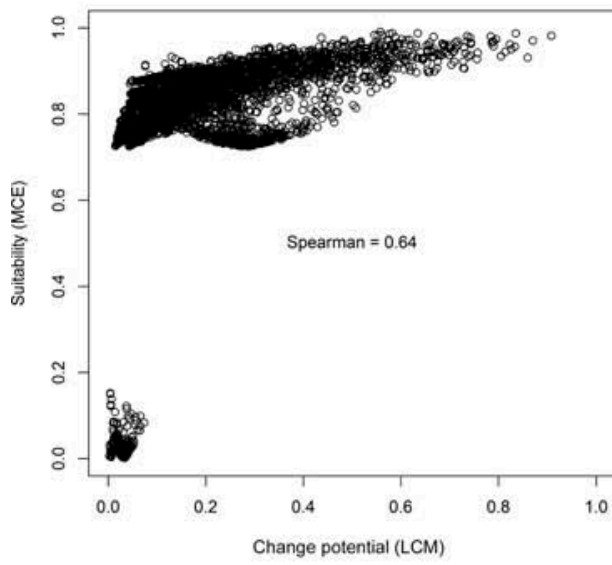

3. Grassland and scrub regeneration

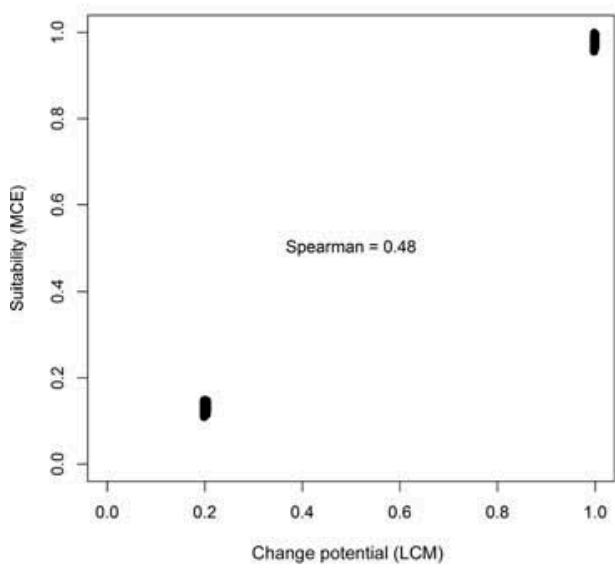

5. New irrigation and rain-fed irrigation change

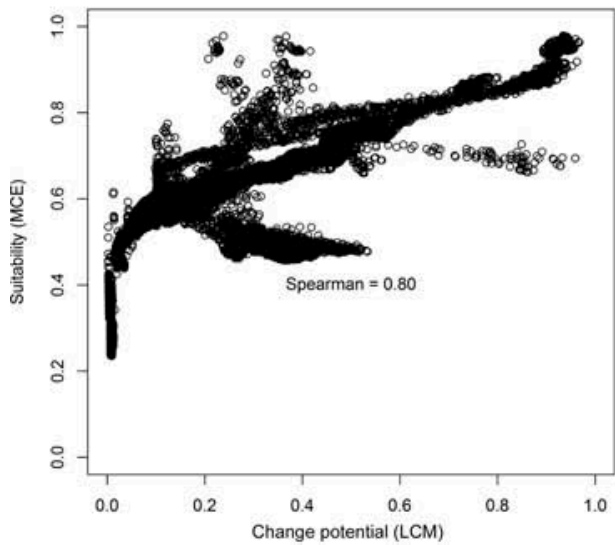

2. Forest regeneration

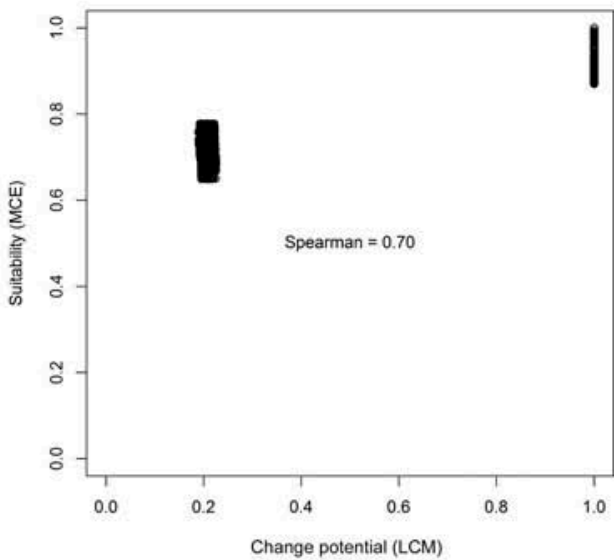

4. Human intervention

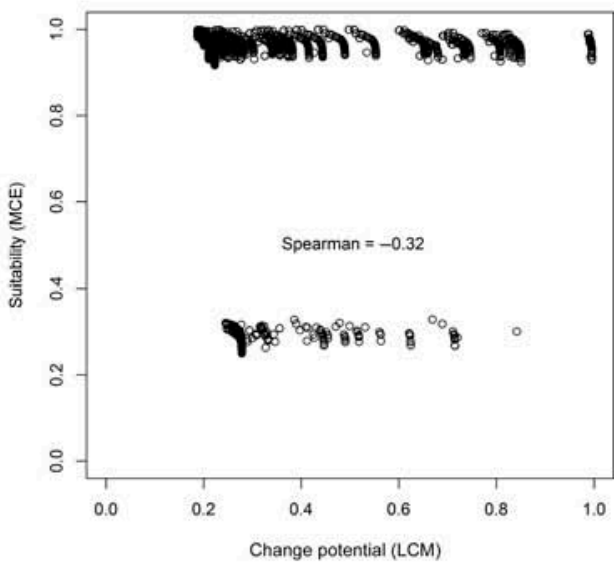

6. New rain-fed crops

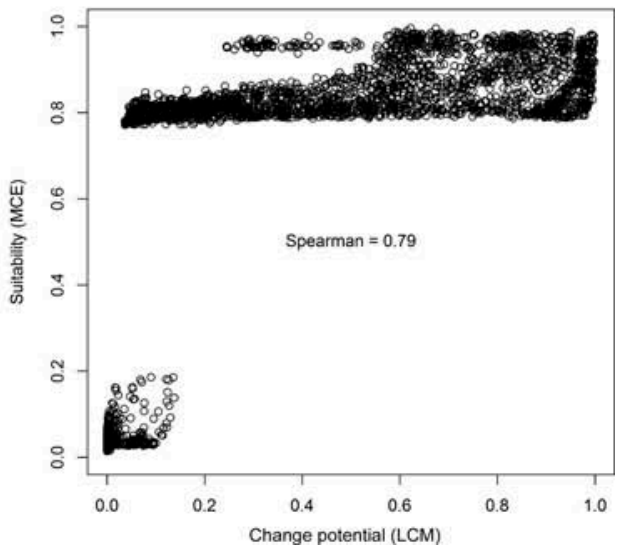

Figure 7. Scattergram for the Spearman correlation for candidate for change areas between the suitability maps and transition potentials (by sub-model). 
change, with Spearman values equal to or greater than 0.7. A value of 0.64 , corresponding to sub-model and suitability map 1 , and a value of 0.48 , corresponding to sub-model and suitability map 3, indicate a moderate correlation. However, the category Unproductive, i.e., sub-model and suitability 4, show a low, negative relationship with Spearman values of -0.32 , indicating that low values of suitability correspond to high values of change potential and vice versa.

Scattergrams show that all of the transition potential maps, except for sub-models 2 and 3 , span the entire spectra of possible values, whereas the suitability maps are restricted to smaller ranges. The isolated point clouds in the scatter plot can be explained by the incorporation of categorical variables into the analysis and also for having obtained degrees of restriction, as used in fuzzy analysis, using evidence likelihood transformation as commented in Section 2.3. MCE seems to be more sensitive to this procedure than LCM is, except for sub-models 2 and 3, where the behavior is similar for both models.

\subsubsection{Agreement between Corine maps and modeled transition potentials versus LUC suitability for candidate for change and persistence areas}

With respect to the candidate for change areas, Figure 8 shows that the AUC values from the MLP results range from 0.506 to 0.718 . Two of the AUC values are close to 0.5 , indicating randomness. The AUC values for the MCE results range from 0.572 to 0.795 , including one value that is close to 0.5 . The maximum difference between the AUC values per category is 0.104 . Nevertheless, it must be pointed out that all of the AUC values are greater in the MCE results, with the exception of the Urban category, i.e., sub-model 1.

For the categories, more homogeneous categories and/or sub-models yielded greater AUC values, as sub-models and suitability maps 1,2,3, and 6. Meanwhile, the AUC values show a weaker fit for unproductive areas, i.e., sub-model and suitability map 4, which may transition to diverse uses, and the results are close to the limit of randomness $(0.5)$ in both models.

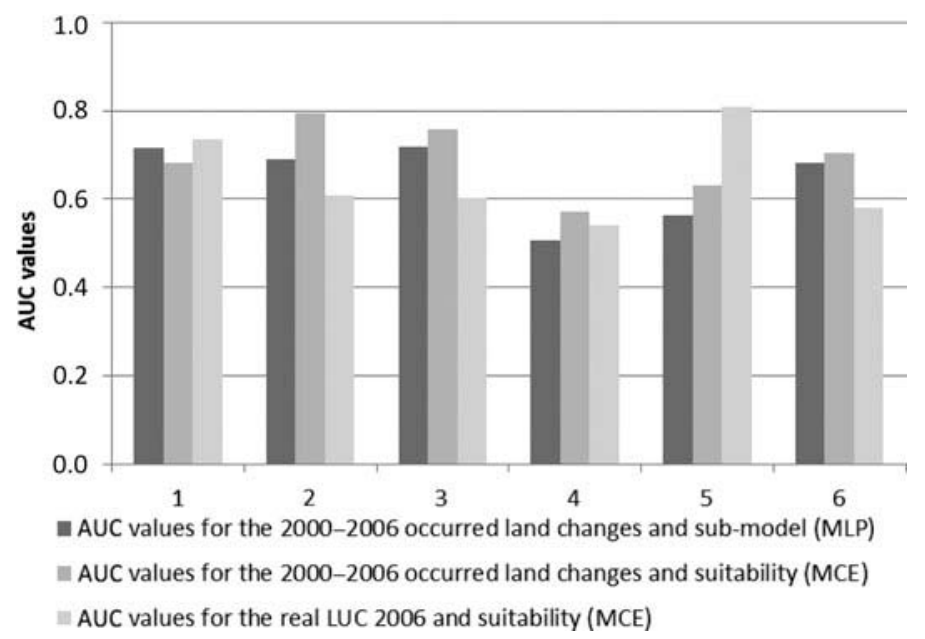

Figure 8. AUC values for the 2000-2006 occurred land changes (0/1) versus the MLP sub-models (left) and MCE suitability maps (middle); the AUC values between the real LUC $2006(0 / 1)$ and the MCE suitability map for the candidate for change and persistence areas (right). The ROC is based on a threshold of 10 , that is, each bin contains $10 \%$ of the candidate region. 
For hand-irrigated areas, i.e., sub-model and suitability map 5, MLP shows random values. Individual transitions are also evaluated to obtain a better understanding of their behavior (AUC values for 3 to 5: 0.699; 4 to 5: 0.696; 6 to 5: 0.487), and the smaller AUC values correspond to areas that have transitioned from nonirrigated to irrigated use.

Compared to the preceding AUC-MCE values, for the total areas, including candidate for change and persistence areas (Figure 8, right column), AUC is greater for urban areas and irrigated areas, and smaller for nonirrigated areas. For unproductive areas of pastureland, the results are similar to the other AUC-MCE values where they are close to 0.5 .

\subsubsection{Agreement between the hard-classified maps and the modeled transition potential versus LUC suitability for candidate for change and persistence areas}

Figure 9 shows that for candidate for change areas, the AUC values for the LCM simulations exceed 0.94 for sub-models $1,4,5$, and 6 , and exceed 0.8 for sub-models 2 and 3 . This finding indicates that LCM allocates the transitions in compliance with the highest values from the transition potential maps. The AUC values for the CA_MARKOV simulations vary between 0.731 and 0.879 , and the value for suitability map 4 is close to randomness, which indicates that this model complies less than LCM with the higher values in their suitability maps to allocate simulated transitions, except for suitability maps 2 and 3.

For the total areas - candidate for change and persistence areas - of suitability maps 1 and 5, the AUC are greater than those for the candidate for change areas. However, the remaining results are smaller compared to the simulated transitions, approaching the limit of randomness. This finding indicates that the CA_MARKOV hard-classified map is less

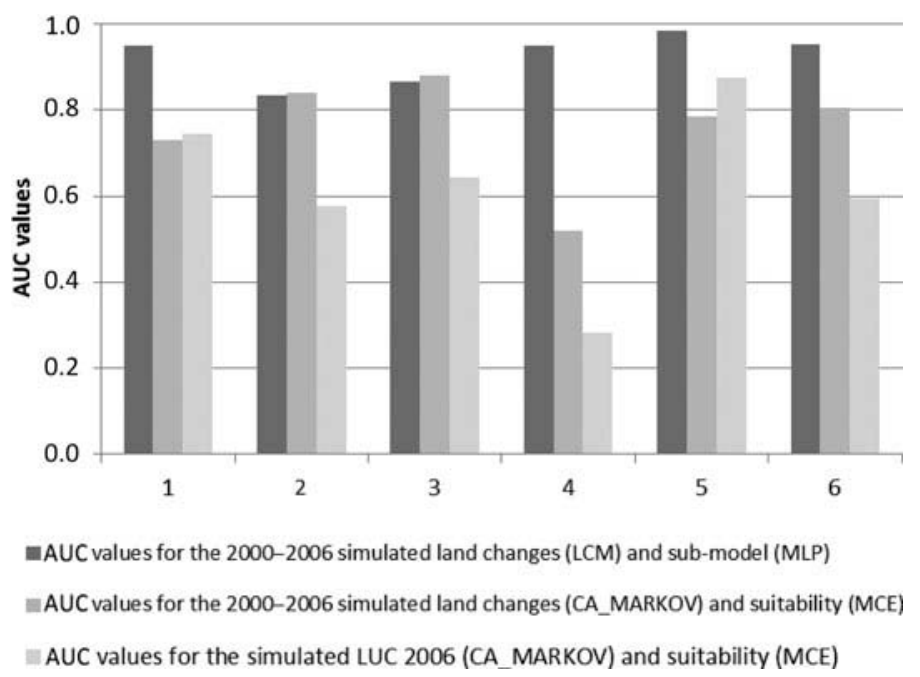

Figure 9. AUC values for 2000-2006 simulated land changes (0/1) in LCM and MLP sub-models (left); the AUC values for the 2000-2006 simulated land changes (0/1) in CA_MARKOV and the suitability maps (MCE for candidate for change areas) (middle). The right column shows the AUC values between the simulated CA_MARKOV LUC $2006(0 / 1)$ and the MCE suitability (candidate for change and persistence areas). The ROC is based on a threshold of 10 , that is, each bin contains $10 \%$ of the candidate region. 
compliant with the higher values from the suitability maps when allocating the total area than when allocating the change areas only.

\section{Discussion}

The following questions must be answered. Which reasons explain the differences (1) between the suitability and transition potential maps themselves, (2) between these intermediate soft-classified maps in terms of predictive ability, and (3) in terms of behaviors when taking into account their own soft-classified maps for allocating changes?

(1) The assessment method applied in this study shows moderate-to-high correlation values between suitability and sub-model change potential maps in grouping the transitions for candidate for change areas, with the exception of one pair. Pontius and Malanson (2005) demonstrate that there can be more variation in output due to the choice of a model's parameters than to the choice of the model. In our example, the parameters used are as similar as possible, as the calibration process is for obtaining soft-classified maps with respect to the explanatory variables and transformation; however, some differences cannot be avoided. The most important difference involves the choice of reference maps for obtaining factors with the purpose of drawing LUC state patterns, one time point calibration, or transition patterns, two time point calibration.

The LUC state patterns in MCE and the transition patterns in MLP are the conceptual core of these soft-classified maps, which justifies this developed comparison. If the patterns in the general state of LUC, i.e., destination category, are not the same as the patterns in the real transition, i.e., origin category to destination category, then the results could be different. This difference might be exacerbated if the real transition is a small area because this small area imposes this pattern to obtain the factors. In addition, the LUC state usually has a larger surface area that is able to show a different pattern.

(2) There are also differences in the predictive ability for the suitability and submodel maps. MCE maps give greater AUC values in all suitability maps except for one, the Urban uses, although the general similarity is reflected in the validation with a real transition (2000-2006), where the AUC values of two types of maps are relatively close.

In our case study, in MLP the reference maps for the calibration period are excluded for the simulation period because Corine transitions from $t_{1}$ to $T$ occur in different areas relative to past transitions. In MCE, the reference maps, i.e., the Corine LUC at time $t_{1}$, may be included in the Corine LUC at time T, corresponding to the persistence areas in $\mathrm{T}$. Consequently, if the patterns of change are not maintained during the calibration and simulation periods, then the results from MLP are less realistic than the MCE results, which are based on the state patterns on the last date of the calibration period. The suitability approach does not consider past changes that occurred during a recent period but rather considers the distribution of land cover that results from the changes that have been made since the beginning of human activities in the study area. 
(3) The new and proposed use of ROC shows that for simulated transitions, LCM complies more with the higher values in the sub-models maps than CA_MARKOV does in the suitability maps, as shown in Figure 9. For the total area, CA_MARKOV gives less compliance to suitability maps, whatever can be explained by persistence areas. Even if the suitability maps include information about persistence areas, it appears to depend more on the LUC state in $t_{1}$ than on the higher values in the suitability maps.

This interpretation cannot go beyond the agreement in terms of allocation because of the relative thresholds of the ROC analysis. Moreover, the assessment with hard-classified maps does not depend solely on intermediate soft-classified maps; it also depends on two important steps. The first step is how the model estimates the quantity of changes, that is, how the Markov matrix works. The second step is how the model allocates these changes and the persistence areas, i.e., how the multi-objective method for conflict resolution works. These aspects inform an absolute hard-classified maps validation procedure which is beyond the scope of this study. Nevertheless, as cited in Section 2.4, when CA_MARKOV allocates changes, the default $5 \times 5$ cellular automata modify the original suitability maps upon weighting the suitability of the neighboring pixels within the filter, what can explain the different behavior in Figure 9.

The discussion from the present case study must be contextualized, taking into account the models, parameters, and data used. Future studies should consider implementing such models exhaustively (Torrens 2011) and running each model in different places and times (Pontius et al. 2008).

\section{Conclusion}

Suitability and transition potential are two types of intermediate soft-classified maps. One of the main differences between the two approaches involves how changes over time are considered. Modeling the LUC state or modeling the transitions lies at the heart of these two approaches in our case study. A model that is calibrated with the state at one time point, i.e., the MCE model, can offer advantages over a model that is calibrated with the difference between two time points, i.e., MLP model, and vice versa.

The suitability-based modeling tool does not explicitly consider recent past changes but implicitly includes the total past changes because reference maps for transforming the variables to factors and for weighting them are the state LUC at $t_{1}$. By contrast, the change potential-based modeling tool evaluates the change potential for each possible transition, where the future potential of the space is split into specific transitions across a finite number of LUC categories. Then, the reference map for creating the factor is the real transition from $t_{0}$ to $t_{1}$.

These two types of reference maps produce important consequences for the factors obtained, which are aggravated if the surfaces of the two reference maps have large differences, and can partly explain the contrasts in the equivalent suitability maps and sub-models.

If the patterns of change are maintained from the calibration period to the simulation period, then modeling the transitions is a more appropriate choice; however, if the patterns of the changes vary, then modeling the suitability map can produce more realistic results. In our case study, the MLP model outperforms the CA_MARKOV model in modeling urban growth because the transition potential map for urban growth captures urban change more accurately than the suitability map does. The CA_MARKOV model 
outperforms the MLP model in the other categories or transitions because the suitability maps of the categories capture the land use and/or land change patterns of these categories more accurately.

Validating intermediate soft-classified maps appears to be a useful step in the initial overview of the accuracy of land change models. The assessment methods applied in this study and their approaches can serve as a companion guide to the more classical hardclassified validation methods. Comparing two models in three stages (comparing their intermediate soft-classified maps to each other, comparing them with observed data, and comparing them with their own simulations) can aid in determining how a model works, the agreement between the values from these maps and those of the observed world and the LUC allocation.

\section{Acknowledgments}

The authors would like to thank the Spanish MINECO for supporting this work through the following project I + D + I: 'Simulaciones geomáticas para modelizar dinámicas ambientales. Avances metodológicos y temáticos'. 2009-2012. BIA2008-00681.

\section{Notes}

1. Descriptions of CA_MARKOV appear in Paegelow and Camacho (2005) and Mobaied et al. (2011). Kamusoko et al. (2009) and Shirley and Battaglia (2008) apply CA_MARKOV for future land change scenarios.

2. An extensive description of the practical applications of LCM can be found in Aguejdad and Houet (2008) and Dang Khoi and Murayama (2010). LCM is used in Silva and Tagliani (2012) to obtain land use changes or 'susceptibility to land change' in a future scenario.

3. A more developed comparison can be found in Paegelow and Camacho (2008) and Mas et al. (2011), who also refer to other models.

4. MINECO, Spain, Project I + D + I 'Simulaciones geomáticas para modelizar dinámicas ambientales. Avances metodológicos y temáticos'. 2009-2012. BIA2008-00681.

\section{References}

Aguejdad, R. and Houet, T., 2008. Modélisation de l'étalement urbain d'une métropole française (Rennes) à l'aide du modèle Land Change: scénarios d'évolutions futures. Symposium Spatial landscape modelling: from dynamic approaches to functional evaluations, 3-5 June 2008 Toulouse. (pp. 12). Toulouse: CNRS.

Conway, T.M. and Wellen, C.C., 2011. Not developed yet? Alternative ways to include locations without changes in land use change models. International Journal of Geographical Information Science, 25 (10), 1613-1631.

Crooks, A.T. and Heppenstall, A.J., 2012. Introduction to agent-based modelling. In: A.J. Heppenstall et al., eds. Agent-based models of geographical systems. Berlin: Springer Verlag, 85-108.

Dang Khoi, D. and Murayama, Y., 2010. Forecasting areas vulnerable to forest conversion in the Tam Dao National Park Region, Vietnam. Remote Sensing, 2, 1249-1272.

Eastman, J.R., et al., 1995. Raster procedures for multi-criteria/multi-objective decisions. Photogrammetric Engineering and Remote Sensing, 61, 539-547.

Eastman, J.R., 1996. Uncertainty and decision risk in multi-criteria evaluation. Implementation for GIS Software Design. UN University International Institute for Software Technology Expert Group. Workshop on Software Technology for Agenda '21. February 26-March 8, Macao, China, Section 8. Decision Support Systems.

Eastman, J.R., 2009. Idrisi Taiga, Guide to GIS and Image Processing, manual version 16.02, Massachusetts: Clark University, (p. 342).

Eastman, J.R., Solorzano, L.A., and Van Fossen, M.E., 2005. Transition potential modeling for landcover change. In: D.J. Maguire, M. Batty, and M.F. Goodchild, eds. GIS, spatial analysis, and modeling. Redland, CA: ESRI, 357-385. 
Gómez, J.L. and Grindlay, A., eds., 2008. Agua, Ingeniería y Territorio: La transformación de la cuenca del río Segura por la Ingeniería Hidráulica. Ministerio de Medio Ambiente, Medio Rural y Marino. Confederación Hidrográfica del Segura.

Gómez Delgado, M. and Barredo Cano, J.I., 2005. Sistemas de Información Geográfica y Evaluación Multicriterio en la ordenación del territorio (GIS and multicriteria evaluation for urban and regional planning). Madrid: Ra-Ma.

Jansen, L.J.M. and Veldkamp, T.A., 2011. Evaluation of the variation in semantic contents of class sets on modelling dynamics of land-use changes. International Journal of Geographical Information Science, 26 (4), 717-746.

Kamusoko, C., et al., 2009. Rural sustainability under threat in Zimbabwe - simulation of future land use/cover changes in the Bindura district based on the Markov-cellular automata model. Applied Geography, 29 (3), 435-447.

Mas, J.F., et al., 2011. Eclairer le choix de modèles de simulation des changements des modes d'occupation et d'usages des sols. Revue Internationale de Géomatique, 21 (3), 405-430.

Mobaied, S., et al., 2011. The use of diachronic spatial approaches and predictive modelling to study the vegetation dynamics of a managed heathland. Biodiversity and Conservation, 20 (1), 73-88.

Paegelow, M. and Camacho Olmedo, M.T., 2005. Possibilities and limits of prospective GIS land cover modeling - a compared case study: Garrotxes (France) and Alta Alpujarra Granadina (Spain). International Journal of Geographical Information Science, 19 (6), 697-722.

Paegelow, M. and Camacho Olmedo, M.T., eds., 2008. Modelling environmental dynamics. Advances in geomatics solutions. Berlin: Springer-Verlag.

Pérez-Vega, A., Mas, J.F., and Ligmann-Zielinska, A., 2012. Comparing two approaches to land use/cover change modeling and their implications for the assessment of biodiversity loss in a deciduous tropical forest. Environmental Modelling and Software, 29 (1), 11-23.

Pontius, R.G. Jr, et al., 2008. Comparing the input, output, and validation maps for several models of land change. Annals of Regional Science, 42 (1), 11-47.

Pontius, R.G. Jr and Malanson, J., 2005. Comparison of the structure and accuracy of two land change models. International Journal of Geographical Information Science, 19, 243-265.

Pontius, R.G. Jr and Parmentier, B., in press. Recommendations for using the relative operating characteristic (ROC). Landscape ecology

Pontius, R.G. Jr and Petrova, S.H., 2010. Assessing a predictive model on land change using uncertain data. Environmental Modelling \& Software, 25, 299-309.

Pontius, R.G. Jr and Schneider, L.C., 2001. Land-cover change model validation by an ROC method for the Ipswich watershed, Massachusetts, USA. Agriculture, Ecosystems \& Environment, 85, 239-248.

Sangermano, F., Eastman, J.R., and Zhu, H., 2010. Similarity weighted instance based learning for the generation of transition potentials in land change modeling. Transactions in GIS, 14 (5), 569-580.

Shirley, L.J. and Battaglia, L.L., 2008. Projecting fine resolution land-cover dynamics for a rapidly changing terrestrial-aquatic transition in Terrebonne Basin, Louisiana, U.S.A. Journal of Coastal Research, 24 (6), 1545-1554.

Silva, T.S. and Tagliani, P.R.A., 2012. Environmental planning in the medium littoral of the Rio Grande do Sul coastal plain - southern Brazil: elements for coastal management. Ocean \& Coastal Management, 59 (April 2012), 20-30.

Steiner, F., McSherry, L., and Cohen, J., 2000. Land suitability analysis for the upper Gila River watershed. Landscape and Urban Planning, 50 (4), 199-214.

Swets, J.A., 1988. Measuring the accuracy of diagnostic systems. Science, 240, 1285-1293.

Torrens, P.M., 2011. Calibrating and validating cellular automata models of urbanization. In: Yang, $\mathrm{X}$., eds. Urban remote sensing. Monitoring, synthesis and modeling in the urban environment. New York, NY: John Wiley \& Sons, 335-345.

Villa, N., et al., 2007. Various approaches for predicting land cover in Mediterranean mountains. Communication in Statistics, 36 (1), 73-86.

Wang, J. and Mountrakis, G., 2011. Developing a multi-network urbanization model: a case study of urban growth in Denver, Colorado. International Journal of Geographical Information Science, $25(2), 229-253$.

Yu, J., et al., 2011. Cellular automata-based spatial multi-criteria land suitability simulation for irrigated agriculture. International Journal of Geographical Information Science, 25 (1), $131-148$. 